\title{
ESTUDOS
}

\section{Psicanálise aplicada ao estudo do cotidiano escolar}

Flávia Zanni Siqueira

\section{Resumo}

Objetiva realizar uma reflexão crítica acerca das possíveis contribuições que o conceito de psicanálise aplicada pode oferecer para descrição e exame do cotidiano escolar. Apresenta algumas de suas definições e empregos ao longo da história do movimento psicanalítico, além de nossa própria compreensão do termo, evidenciando a viabilidade de um método psicanalítico de investigação das formas de enlaçamento social no contexto educacional. Procura articular os aspectos metodológicos e operatórios do conceito, principalmente a partir de escritos de Freud, a textos que refletem sobre a produção científica no âmbito da educação, especialmente os publicados por José Mário Pires Azanha. Conclui que a partir do conceito de psicanálise aplicada é possível compreender os elementos que tornam particulares as interações entre os agentes escolares, em suas atividades cotidianas, em relação aos seus funcionamentos psíquicos.

Palavras-chave: psicanálise em educação; cotidiano escolar; pesquisa psicológica. 


\section{Abstract \\ Psychoanalysis applied to a study of everyday school life}

The present work aims at a critical reflection about the contributions that the applied psychoanalysis concept can bring to describe and assess the everyday school life. The text introduces some definitions and usages in the history of the psychoanalytic movement, as well as the authors' own comprehension, highlighting that it is viable to apply a psychoanalytical method of investigation to the educational context. The article seeks to link the methodological and the operational aspects of the concept, especially concerning Freud studies, to texts that aimed at the scientific production in the educational area, especially the ones published by Azanha. It concludes that the applied psychoanalysis concept can make it possible to understand which elements lead to particular interactions of the school agents in their daily activities, according to how their minds work.

Keywords: psychoanalysis in education; everyday school life; psychological research.

O conceito de psicanálise aplicada postulado por Freud, que, segundo Roudinesco e Plon (1998, p. 605), "desde muito cedo teve o sentimento de estar desenvolvendo ideias passíveis de concernir a campos externos ao estudo do funcionamento psíquico, como a criação literária ou artística", foi e é objeto de muita polêmica dentro do campo psicanalítico e de críticas contundentes fora dele. Sua definição e os desdobramentos de seu emprego sofreram diversas alterações ao longo dos anos, de maneira que se torna imprescindível retomar algumas de suas ocorrências na história do movimento psicanalítico antes de empreender um esforço para operacionalizá-lo numa discussão metodológica.

Em razão de um processo aberto em Viena contra Theodor Reik, em 1926, por violação da lei austríaca que determinava que somente pessoas com o título de médico poderiam tratar de pacientes (lei contra o charlatanismo), ${ }^{1}$ iniciou-se um debate aberto no âmbito das sociedades de psicanálise sobre os domínios de seu campo. A controvérsia começou como uma acusação jurídica e adiantou-se como uma necessidade, dentro do campo psicanalítico, de se estabelecer uma demarcação clara sobre "o que é uma psicanálise e quais exigências ela faz ao analista", além de considerar "as relações, muito longe de serem simples, entre a psicanálise e a medicina" (Freud, 1926b, p. 256).

Nesse mesmo ano, Freud publicou seu artigo sobre a análise leiga, cujo pós-escrito versava diretamente acerca do episódio envolvendo
1 Conforme informa Strachey, na nota do editor inglês da Edição Standard Brasileira, Freud (1926a) interveio diretamente no caso, que, após uma investigação preliminar, foi encerrado por falta de provas. 
Reik, trazendo à tona um aspecto essencial a respeito da discussão sobre a psicanálise aplicada, a saber: a diferença, por ele estabelecida, entre a teoria e a prática psicanalíticas.

A psicanálise é uma parte da psicologia; não da psicologia médica no velho sentido, não da psicologia de processos mórbidos, mas simplesmente da psicologia. Certamente não é o todo da psicologia, mas sua subestrutura e talvez mesmo todo o seu alicerce. A possibilidade de sua aplicação a finalidades médicas não nos deve desorientar. A eletricidade e a radiologia também têm sua aplicação médica, mas a ciência à qual ambas pertencem é, não obstante, a física. (Freud, 1926a, p. 242).

Nesse trecho, Freud marca de maneira categórica sua posição no que diz respeito à distinção entre teoria e prática psicanalíticas, que culminou na sua afirmação de que "a verdadeira linha de divisão situa-se entre a análise científica e suas aplicações igualmente nos setores médico e não-médico" (Freud, 1926a, p. 247). Longe de ser um posicionamento definitivo dentro do campo psicanalítico, essa formulação freudiana aponta para a compreensão da psicanálise aplicada - com finalidade terapêutica ou não - como uma modalidade da psicanálise científica, exposta por ele como sinônimo de metapsicologia. Ao longo desse mesmo texto, entretanto, o autor nuança a separação entre o amadurecimento teórico e a prática terapêutica, apenas ponderando ser preciso assegurar-se de que "a terapia não destruirá a ciência" (Freud, 1926a, p. 244).

Na psicanálise tem existido desde o início um laço inseparável entre cura e pesquisa. O conhecimento trouxe êxito terapêutico. Era impossível tratar um paciente sem aprender algo de novo; foi impossível conseguir nova percepção sem perceber seus resultados benéficos. Nosso método analítico é o único em que essa preciosa conjunção é assegurada. [...] Essa perspectiva de ganho científico tem sido a feição mais orgulhosa e feliz do trabalho analítico. (Freud, 1926a, p. 246).

A despeito dessa demarcação tão clara entre teoria e prática, a posição freudiana acerca da psicanálise aplicada ao campo não médico foi reticente: por um lado, Freud manifestou uma vontade explícita de estender o conhecimento psicanalítico a outros campos - e a concretizou em inúmeros trabalhos, como "Delírios e sonhos na Gradiva de Jensen", "Móises de Michelangelo", "Totem e tabu", entre outros -; por outro, ele expressou em várias ocasiões, especialmente em sua correspondência, o receio de um certo caráter diletante dessa extensão (cf. Plon, 1999).

É inegável, contudo, que a definição de psicanálise aplicada defendida por Freud - separada da metapsicologia - não foi a que prevaleceu ao longo dos anos. Plon (1999, p. 93) aponta que entre os psicanalistas de língua inglesa a divisão foi modificada, sendo atribuída "plena legitimidade epistemológica à psicanálise aplicada desde que não venha a ter qualquer relação com a prática terapêutica"; entre os psicanalistas de língua francesa, a psicanálise aplicada passou a ser uma expressão "correlativa de uma utilização de denominação de psicanálise leiga para designar unicamente o exercício da prática analítica terapêutica por não-médicos" (p. 94). Em ambos os casos, o eixo organizador 
da divisão deslocou-se do par teoria e prática, como proposto por Freud, para gravitar em torno da noção de terapia.

Em 1958, ao publicar o artigo "Juventude de Gide ou a letra e o desejo", Lacan apontou as inúmeras confusões de entendimento que a qualificação "aplicada" conferiu desde o início à psicanálise. A preocupação do autor se justificava pelo fato de, especialmente na França, sob o título de psicanálise aplicada, terem sido publicados diversos trabalhos psicobiográficos e patográficos, ${ }^{2}$ muitos deles desprovidos de rigor. Mais tarde, na ata de fundação da Escola Freudiana de Paris, em 1965, Lacan enunciou uma nova divisão, em três partes, tentando suprimir a confusão apontada anteriormente (cf. Plon, 1999): psicanálise pura, para designar a psicanálise didática; psicanálise aplicada, para fazer referência à terapêutica ou à clínica; e recenseamento do campo freudiano, para abranger a articulação da psicanálise com as ciências afins:

A psicanálise só se aplica, em sentido próprio, como tratamento e, portanto, a um sujeito que fala e que ouve. Fora desse caso, só pode tratar-se de método psicanalítico, aquele que procede a decifração dos significantes, sem considerar nenhuma forma de existência pressuposta do significado. (Lacan, 1998, p. 758, grifo nosso).

Tanto a postura reticente de Freud quanto a tentativa de reordenação de Lacan no que concerne à psicanálise aplicada apontam para as várias discussões e impasses que se acumularam desde sua primeira formulação. Dessas críticas, vamos refletir sobre duas que consideramos mais frequentes: os problemas envolvidos na analogia entre processos psíquicos individuais e coletivos e a pertinência da interpretação analítica de material que não provém do emprego direto da associação livre, ou seja, supostamente distante de uma produção inconsciente.

Sobre a primeira crítica é preciso pontuar, antes de mais nada, a posição freudiana acerca do interesse da psicanálise sobre os processos coletivos. Na extensão de sua obra, são recorrentes os exemplos em que o autor se apropriou de discussões sociológicas e antropológicas para debater aspectos teóricos da psicanálise, especialmente em sua relação com a religião, com os fenômenos de massa e com as formas de enlaçamento social. Freud negou a divisão entre indivíduo e sociedade, consolidando sistematicamente sua concepção bio-psico-social de sujeito.

O contraste entre a psicologia individual e a psicologia social ou de grupo, que à primeira vista pode parecer pleno de significação, perde grande parte de sua nitidez quando examinado mais de perto. É verdade que a psicologia individual relaciona-se com o homem tomado individualmente e explora os caminhos pelos quais ele busca encontrar satisfação para seus impulsos instintuais; contudo, apenas raramente e sob certas condições excepcionais, a psicologia individual se acha em posição de desprezar as relações desse indivíduo com os outros. Algo mais está invariavelmente envolvido na vida mental do indivíduo, como um modelo, um objeto, um auxiliar, um oponente, de maneira que, desde o começo, a psicologia individual, nesse sentido ampliado mas inteiramente justificável das palavras, é, ao mesmo tempo, também psicologia social. (Freud, 1921, p. 81).
${ }^{2} \mathrm{O}$ primeiro diz respeito à interpretação das obras em função da vida do autor e o segundo se refere à análise de escritores com base em experiências patológicas obtidas a partir de temas recorrentes de suas obras. 
Se tomarmos o próprio conceito de inconsciente, como postulado por ele, e a ideia de constituição do sujeito fundamentada na passagem pelo complexo de Édipo, fica evidente a impossibilidade do ideal individual, a impossibilidade de uma psicologia sem lastro nos fenômenos sociais. É a partir da conceituação desse "conjunto de desejos amorosos e hostis que a criança experimenta relativamente aos pais" (Laplanche, Pontalis, 1983, p. 116) que Freud evidenciou o papel essencial das identificações na estruturação da personalidade, mostrando que a organização triangular, e as relações de desejo e interdição entre os vértices do triângulo, é o mecanismo psíquico que permite a inserção do sujeito na cultura.

Embora a ligação necessariamente lógica entre sujeito e sociedade nos pareça bem estabelecida, ainda persiste a discussão acerca da relação analógica estabelecida entre eles pela psicanálise. Em outras palavras, tratase de examinar onde se ancora a presença, até bastante ostensiva, do que Plon chama de "deriva interpretativa" e "extensão aleatória do raciocínio analógico", críticas frequentes dirigidas aos trabalhos em psicanálise aplicada. É preciso pontuar, contudo, que tais características não são exclusividade desse tipo de trabalho, mas deitam raízes na metapsicologia freudiana. Segundo o autor, isso decorre do caráter dualista do pensamento freudiano.

\begin{abstract}
Dualismo entre a teoria do trauma que atribui a um acontecimento real a origem da neurose e a teoria do fantasma cuja concepção historiográfica apressada e rudimentar tende a dizer que substituiu a primeira em 1897 quando o próprio Freud, na sua Introdução à psicanálise, e também muito mais tarde, particularmente em Além do princípio do prazer, não cessa de levar em conta os dois registros. (Plon, 1999, p. 103).
\end{abstract}

Mais recentemente, ao tratar da relação entre psicanálise e cultura, Mezan (2002, p. 318, grifo nosso) afirmou que "a psicanálise lida com o funcionamento psíquico do ser humano em sociedade, pela boa e simples razão de que não há outro: até Robinson Crusoé, em sua ilha, trazia consigo as técnicas e crenças da sociedade inglesa de 1710". Sujeito e sociedade não podem, portanto, ser tomados como elementos antagônicos, mas devem ser concebidos a partir de uma relação de interdependência; como a fita de Moebius, ${ }^{3}$ eles compõem um mesmo plano, são o mesmo lado, sem que, contudo, um possa ser reduzido ao outro. Da mesma forma, a relação entre processos psíquicos individuais e coletivos - e a analogia estabelecida entre eles - não deve ser entendida a partir da noção de opostos.

Logo no início da República, Platão propõe utilizar aquilo que acontece na cidade para compreender a natureza da justiça, que no início do diálogo estava sendo atribuída à alma - a questão é saber quem é mais feliz, o homem justo ou o injusto. A um certo momento, Sócrates lembra que talvez seja interessante investigar isso não só na alma individual, mas também na vida social; como a justiça é uma só, se pudermos decifrá-la naquilo que a polis escreve com letras maiúsculas, ficará mais fácil compreender o que se passa na alma dos homens, na qual esse conceito está colocado em letras minúsculas. Esse é o princípio que organiza as pesquisas da psicanálise aplicada: ela é capaz de ler, nas maiúsculas da cultura, coisas que podem ter validade também nas minúsculas da vida psíquica individual. (Mezan, 2002, p. 318). 
No entanto, o próprio autor admite a legitimidade das críticas a algumas produções psicanalíticas que estabelecem uma relação de identidade entre sujeito e sociedade: "(...) muitos desses exercícios [de psicanálise aplicada] são realmente estereotipados. O leitor já sabe o que vai encontrar: o complexo de Édipo, os objetos parciais, as pulsões..." (Mezan, 2002, p. 319). Assim, o embaraço que envolve a noção de psicanálise aplicada, muitas vezes associada dentro e fora do campo psicanalítico à ideia de uma "deriva interpretativa" - e seu efeito direto nas produções do campo: a recusa do material não clínico, em sua acepção estrita -, pode ser compreendida, embora, não justificada; não de todo, pelo menos.

A falta de rigor e o excesso de previsibilidade encontrados em vários textos de psicanálise aplicada, entretanto, não são o cerne da diferença com relação aos trabalhos conduzidos por Freud nessa área. Os estudos freudianos tangentes às ciências afins buscavam, principalmente, imprimir avanços teóricos à psicanálise, que estava em pleno desenvolvimento.

Perfeitamente consciente das fraquezas desses pontos do método, ele [Freud] visava outra coisa cada vez que se autorizava a fazer incursões por domínios externos à psicanálise. Ele tinha por objetivo simplesmente desenvolver pontos em sua teoria que estavam obscuros até então [...]. E é nesse ponto, o ponto do objetivo, que se inscreve a diferença entre a psicanálise aplicada produzida por Freud e aquela desenvolvida por seus alunos e sucessores. (Plon, 1999, p. 104, grifo do autor).

Evidentemente, há outro grande grupo de trabalho atento aos cuidados fundamentais da produção científica - formulação de hipóteses plausíveis e devidamente ancoradas no referencial teórico, testagem de sua coerência a partir de outros elementos do material utilizado, questionamento acerca de eventuais equívocos de interpretação e arguição da própria implicação do pesquisador no material pesquisado, produzida a partir da projeção e da contratransferência (cf. Mezan, 2002) -, que apresenta resultados bastante interessantes em psicanálise aplicada. O interesse nesse tipo de produção pode ser resumido no fato de a psicanálise privilegiar a dimensão inconsciente na análise dos fenômenos, o que pode promover uma contribuição tanto à metapsicologia quanto ao estudo dos objetos das ciências afins.

[...] a possibilidade de isolar os elementos de subjetividade empregados nas práticas sociais para, ao mesmo tempo, esclarecer o que é residual nessas práticas, quer dizer, aquilo que, nessas práticas, escapa à análise sociológica ou econômica e enriquece por sua vez nosso conhecimento teórico das engrenagens desta subjetividade que tais práticas podem fazer aparecer. (Plon, 1999, p. 106).

Sobre a segunda crítica, que coloca em xeque a pertinência epistemológica da interpretação operada fora do enquadre estritamente clínico, talvez baste dizer que o sujeito do inconsciente está presente em todo discurso, seja ele produzido num divã ou num espaço público. O que o método psicanalítico propõe é uma escuta ancorada em sua ética e operadores teóricos, que procura compreender o sujeito, enredado nos fenômenos sociais e políticos, em relação ao seu desejo. Freud (1901) mostrou com clareza essa relação ao 
apontar manifestações do inconsciente nos acontecimentos da vida diária, como em Psicopatologia da vida cotidiana.

Ao longo desse trabalho, o autor procurou demonstrar a possibilidade de estender suas descobertas acerca dos funcionamentos psicopatológicos a episódios triviais da vida cotidiana: substituição e esquecimento de nomes próprios, lapsos de fala e de leitura, chistes, entre outros. O resultado final desse esforço teórico foi a exposição de uma equivalência entre a produção de atos falhos e a de imagens oníricas, o que confirmou a tese freudiana sobre as realizações anímicas, calcadas na descrição dos processos primários e secundários. Em outras palavras, a conformidade estabelecida entre os mecanismos de produção dos atos falhos e de formação dos sonhos sustenta a premissa fundamental da psicanálise: a divisão dos processos mentais em conscientes e inconscientes.

\begin{abstract}
Dessa conformidade é possível extrair uma importante conclusão: o modo peculiar de trabalho cuja mais notável realização se discerne no conteúdo dos sonhos não pode ser atribuído ao estado de sono da vida anímica, uma vez que temos nos atos falhos provas tão abundantes de que ele também opera durante a vida de vigília. A mesma relação também nos proíbe de presumir que esses processos psíquicos que nos parecem anormais e estranhos sejam condicionados por uma desintegração radical da atividade anímica ou por estados patológicos de funcionamentos. (Freud, 1901, p. 271).
\end{abstract}

Ao estender a análise psicanalítica para os acontecimentos ordinários da vida, além de ampliar o domínio da clínica, Freud também apontou um caminho criterioso para os trabalhos em psicanálise aplicada, conforme sua própria definição, ao campo não médico. Dessa foma, o autor abriu definitivamente um espaço em sua metapsicologia para o estudo de processos que não são caracterizados pela morbidade, nuançando a fronteira entre "normal" e patológico. Com isso, Freud instituiu um método para investigação de qualquer manifestação psíquica baseado na ideia de que "os fenômenos podem ser rastreados a um material psíquico incompletamente suprimido, o qual, apesar de ser reprimido pela consciência, ainda assim não foi despojado de toda sua capacidade de se expressar" (Freud, 1901, p. 272, grifo do autor).

Nesse ponto, já temos material suficiente para enunciar nosso propósito, no que tange ao emprego do conceito de psicanálise aplicada ao estudo do cotidiano escolar. Aspiramos uma contribuição operacional, ancorada no corpo teórico psicanalítico, para a descrição e o exame do cotidiano escolar; um método psicanalítico de investigação das formas de enlaçamento social no contexto educacional. Compartilhamos com Freud a acepção do termo "psicanálise aplicada", no que diz respeito a sua separação em relação à noção de metapsicologia; portanto, assim como ele, o compreendemos a partir do eixo organizador teoria e prática. Entretanto, consideramos importante aproximar desse sentido do termo a noção lacaniana de método de investigação.

Essa escolha se dá em função dos avanços teóricos obtidos desde a formulação inicial do termo. Ao percorrer porções de território das 
ciências afins, Freud almejava aprimorar a elaboração do conjunto de modelos conceituais psicanalíticos. Com seu aporte teórico bem estabelecido, consideramos, juntamente com Starobinski (1980, p. XXXVIII), em seu comentário de abertura ao ensaio de Ernest Jones sobre Hamlet e Édipo, que "o método é dado, não é posto em questão: trata-se apenas de provar que é operatório". Mezan (2002, p. 371) expôs alguns operadores essenciais à psicanálise aplicada para o estudo dos fenômenos culturais, sociais e políticos: "onde estão as pulsões? Que destinos elas têm? A que defesas estão submetidas? Qual é o destino das fantasias sexuais e agressivas?".

Nesse mesmo texto, o autor reconhece a necessidade de se debater os aspectos metodológicos envolvidos nos exercícios de psicanálise aplicada para evitar os equívocos que contribuíram para o aviltamento do termo ao longo dos anos. Os dois primeiros mantêm relações com a prática científica geral: o problema de se utilizar " 'ferramentas de grosso calibre' - afirmações muito genéricas a respeito da psique [por exemplo, o conceito de sublimação ou de coerção das pulsões] - para dar conta da singularidade de uma manifestação especial" (Mezan, 2002, p. 374) e a necessidade de se executar procedimentos comparativos para não incorrer no erro de que "a análise seja simplesmente projeção das fantasias do analista sobre o assunto analisado" (p. 375). O terceiro, por sua vez, é restrito à psicanálise aplicada e

consiste na busca sistemática do que é inconsciente, já que esse é o objeto próprio da nossa disciplina. O que significa dizer que existe inconsciente numa obra de cultura? Antes de mais nada, que ela contém sentidos ou relações latentes, não legíveis na superfície que expõe ao receptor [...] o inconsciente se constrói assim entre os dois parceiros [obra da cultura, entendida também em seu sentido institucional, e pesquisador], e o equivalente disso na análise da obra é o surgimento de uma hipótese interpretativa, apta a desvendar nela um aspecto até então insuspeitado e capaz de ser elucidado com o instrumental psicanalítico. (Mezan, 2002, p. 376, grifo do autor).

Colocada, ainda que brevemente, a temática da psicanálise aplicada, em seus aspectos metodológicos e operatórios, gostaríamos de avançar para a segunda metade da nossa proposta: o estudo do cotidiano escolar. Na literatura consultada sobre análise da produção científica no âmbito da educação, as críticas encontradas referem-se, principalmente, ao caráter abstrato das reflexões. Ao analisar o conjunto de publicações sobre o discurso pedagógico, entendido, nesse caso, como um conjunto de produções intelectuais sistematizadas, Nagle (1976) avaliou que elas podem ser reunidas em dois grandes grupos de interesse.

De um lado, encontram-se textos que relacionam educação e temas de cunho mais geral (como democracia, Estado etc.), de outro, textos que discutem temas específicos do universo educacional (como currículo, avaliação etc.). O problema apontado pelo autor nessas produções é a falta de trabalhos que estabeleçam relação entre os dois grupos, já que, segundo ele, o primeiro não atinge as condições concretas dos fenômenos estudados 
(a prática docente, em última análise) e o segundo, frequentemente, trata as questões técnico-pedagógicas reduzidas a generalidades.

Apenas este esboço já permite tirar uma conclusão: a inexistência de estudos e análises intermediários, de pontos de ligação entre temas amplos e restritos [...]. Tal fato concorre para o empobrecimento das análises, uma das características mais marcantes das produções do discurso pedagógico. E empobrecimento, no caso, significa, basicamente, isolar aspectos gerais de aspectos restritos, como se estes fossem dois mundos incomunicáveis, e, além disso, dois mundos em que as generalidades possam dar conta de sua compreensão. (Nagle, 1976, p. 17).

Outro autor indica falhas semelhantes nessa literatura, evidenciando o impacto operado pelas frequentes cisões entre "temas amplos e restritos" nas pesquisas educacionais para a produção de conhecimentos acerca do universo escolar brasileiro. Em inúmeros trabalhos, Azanha apontou as consequências problemáticas de se privilegiar as operações formais de princípios abstratos em detrimento do exame das práticas escolares concretas nessas investigações.

[...] temos insistido na crítica ao estilo de estudos da educação brasileira, no qual os autores operam com categorias demasiado abstratas para permitirem descrições confiáveis das práticas escolares concretas. O defeito desses estudos está, justamente, no fato de que, nas generalidades em que permanecem, os autores não estão autorizados às qualificações e classificações que fazem de uma prática desconhecida, porque inacessível a partir das posições em que eles se situam. (Azanha, 1992, p. 57).

Não podemos deixar de ressaltar a paridade dessa crítica àquela formulada por Mezan (2002) acerca da psicanálise aplicada: "categorias demasiado abstratas" nos parece equivalente a "ferramentas de grosso calibre". No contexto educacional, Azanha $(1992,1995)$ elucidou sua avaliação acerca da produção científica na área, evidenciando o efeito encobridor das análises correntes sobre o ambiente escolar.

Que é o "aluno reprovado"? Esta entidade (cuja presença maciça nas estatísticas constitui evidência da crise escolar) é fruto de práticas escolares cuja formação, transformação e correlatos podem passar desapercebidos [...]. O predicado "ser reprovado" não existe a não ser pelas práticas que o produziram. (Azanha, 1995, p. 71).

Este exemplo deixa à mostra um outro ponto que nos parece aproximar as preocupações desses dois autores nos âmbitos da educação e da psicanálise, por onde gostaríamos de introduzir a ideia de cotidiano escolar - trata-se da noção de "prática". Ao argumentar em favor da necessidade de se lançar mão de teorias educacionais reconhecidamente bem estabelecidas para orientar estudos descritivos sobre as práticas escolares - uma vez que esses não são considerados "neutros" -, Azanha (1987) nos lembra, por exemplo, que o ofício do professor é caracterizado por um conjunto de regras não exaustivas, ou seja, regras que mais norteiam que determinam a atividade, uma vez que a ação educativa se define por 
um saber fazer, por uma regulação que aumenta a probabilidade de um resultado satisfatório, mas não o garante.

A atividade de ensinar parece mais um exemplo de saber como do que saber que, isto é, trata-se antes de um saber fazer do que de conhecer certas regras e aplicá-las. Se dissermos que alguém sabe ensinar, isto significa necessariamente que obtém êxito no seu propósito e só acessória e eventualmente que segue esta ou aquela regra. (Azanha, 1987, p. 76, grifo do autor).

Por essa razão, pela maneira original com que cada professor constrói seu arcabouço prático, não é possível apreender as experiências vivenciadas pelos agentes na instituição escolar a partir de "categorias demasiado abstratas". Não é possível, por exemplo, pesquisar o conteúdo programático dos cursos de formação de professores e depreender, exclusivamente a partir desse material, a atividade docente concreta. Em outras palavras, a pesquisa educacional deve atentar para as complexas relações sociais e psicológicas que se desenvolvem e que estruturam, de maneira singular, o cotidiano escolar. Mezan (2002) traz à tona a mesma inquietação ao tratar, em termos equivalentes à "prática", sobre a questão da "forma" em relação à psicanálise aplicada.

O equívoco comum [na análise de uma formação cultural] é ir diretamente para o conteúdo transindividual, esquecendo justamente o que dá à obra ou à instituição a sua especificidade, que é a forma [...] na forma, temos elementos que são singulares e outros que são transindividuais ou coletivos. (Mezan, 2002, p. 377, grifo do autor)

É nessa conjunção, do que é singular com o que é compartilhado, que o cotidiano se estrutura; e a importância do seu estudo decorre do fato de que "não há realidade humana desvinculada da realidade concreta de uma cotidianidade" (Azanha, 1992, p. 62). As atividades que se desenrolam no cotidiano, incluído aí o cotidiano escolar, exprimem os conteúdos nem sempre insignificantes da incansável repetição de práticas, aspecto marcante das instituições e, do ponto de vista psicanalítico, elemento importante da análise.

O cotidiano humano não se resume, como na vida animal ou vegetal, na sucessão diária de atos ou movimentos visando à simples sobrevivência física [...] no caso humano, o cotidiano, até mesmo na sua mais rudimentar manifestação, extrapola os limites do físico e exibe profundamente a marca do social e por isso do histórico. (Azanha, 1992, p. 63).

Entretanto, é preciso pontuar que "a passagem de observações para hipóteses só ocorre pela intervenção de alguma teoria e não pelo simples acúmulo daquelas" (Azanha, 1992, p. 74, grifo do autor). Não se trata, portanto, de definir simplesmente uma metodologia de coleta de dados, mas de, ancorado num referencial teórico, incidir o olhar para pontos de interesse do cotidiano; pontos que possam contribuir para a compreensão 
de processos psicológicos, sociais, políticos ou históricos a partir do tratamento de observações da cotidianidade, com base em premissas teóricas bem fundamentadas.

A potencialidade reveladora dos objetos da cotidianidade precisa ser teoricamente ativada para que as possíveis revelações ocorram. De nada adiantaria simplesmente postular a fecundidade do estudo da vida cotidiana para o conhecimento do homem sem indicar como é possível obter esse conhecimento a partir da cotidianidade. Para isso, é indispensável a formulação de teorias que indiquem seletivamente o que descrever e analisar aquilo que, sem elas, seria um caos factual. (Azanha, 1992, p. 66).

Insistimos anteriormente na acepção da psicanálise aplicada como: (a) algo distinto da metapsicologia e (b) um método de investigação. Em princípio, nossa afirmação poderia opor-se aos pontos defendidos por Azanha para o estudo do cotidiano escolar. Assim, consideramos necessário pontuar nossa compreensão de método de investigação psicanalítico como um aspecto separado da metapsicologia, porém jamais considerado independentemente dessa. Em outras palavras, quando apresentamos a psicanálise aplicada em seu aspecto operatório, não a entendemos a partir de uma posição meramente instrumental, em que a teoria psicanalítica pudesse ser diretamente empregada como meio para se alcançar algum resultado escolar desejado.

Muito embora a denominação "aplicada" possa conter essa relação - e boa parte dos equívocos dos trabalhos em psicanálise aplicada se assenta na possibilidade de compreender a ligação aplicada-empregada, a partir da ideia de "utilizar-se de" -, não é dessa forma que propomos seu entendimento. Ao contrário, sugerimos que o desdobramento da compreensão de "aplicada" se dê pela via do "valer-se de". Assim, concebemos a psicanálise aplicada ao estudo do cotidiano escolar não como um saber referencial, mas como uma possibilidade de mobilização, de provocação no contexto educacional. Não a entendemos, portanto, como um método que tenha valor em si mesmo, mas como uma forma de se aproximar dos fenômenos escolares, levando-se em consideração a ética e os operadores teóricos psicanalíticos. Assim, Mezan (2002, p. 374, grifo do autor) resume essa aproximação a partir da ideia de escuta psicanalítica.

No caso da psicanálise, o processo começa com a percepção, pelo investigador, de uma nota dissonante. É a impressão de que alguma coisa 'não bate bem'. Esse é sempre o ponto de partida de qualquer processo interpretativo: é assim que escutamos.

Entendemos, dessa forma, que o conceito de psicanálise aplicada detém todas as exigências necessárias para empreender uma descrição e uma análise do cotidiano escolar. Consideramos que a partir desse referencial é possível compreender os elementos que tornam particulares as interações entre os agentes escolares, em suas atividades cotidianas, em relação aos seus funcionamentos psíquicos. 


\section{Referências bibliográficas}

AZANHA, J. M. P. Educação: alguns escritos. São Paulo: Companhia Editora Nacional, 1987.

. Uma ideia de pesquisa educacional. São Paulo: Edusp, 1992.

. Educação: temas polêmicos. São Paulo: Martins Fontes, 1995.

FREUD, S. Sobre a psicopatologia da vida cotidiana: esquecimentos, lapsos de fala, equívocos na ação, superstições e erros.

Trad. Jayme Salomão. Rio de Janeiro: Imago, [1901] 1977.

(Edição Standard Brasileira das Obras Psicológicas Completas de Sigmund Freud, VI).

Psicologia das massas e análise do eu. Trad. Jayme Salomão.

Rio de Janeiro: Imago, [1921] 1977. (Edição Standard Brasileira das

Obras Psicológicas Completas de Sigmund Freud, XVIII).

A questão da análise leiga: conversações com uma pessoa

imparcial. Trad. Jayme Salomão. Rio de Janeiro: Imago, [1926a] 1977.

(Edição Standard Brasileira das Obras Psicológicas Completas de

Sigmund Freud, XX).

. Breves escritos (1938-1931): dr. Reik e o problema do

charlatanismo. Trad. Jayme Salomão. Rio de Janeiro: Imago, [1926b]

1977. (Edição Standard Brasileira das Obras Psicológicas Completas

de Sigmund Freud, XXI).

LACAN, J. Escritos. Trad. Vera Ribeiro. Rio de Janeiro: Jorge Zahar, 1998.

LAPLANCHE, J.; PONTALIS, J-B. Vocabulário da psicanálise.

Trad. Pedro Tamen. 7. ed. São Paulo: Martins Fontes, 1983.

MEZAN, R. Psicanálise e cultura, psicanálise na cultura. In:

Interfaces da psicanálise. São Paulo: Cia das Letras, 2002. p. 317-392.

NAGLE, J. Discurso pedagógico: uma introdução. In: NAGLE, J. (Org.).

Educação e linguagem: para um exame do discurso pedagógico.

São Paulo: Edart, 1976. p. 11-42.

PLON, M. A face oculta da análise leiga. Ágora: Estudos em Teoria

Psicanalítica, Rio de Janeiro, v. 2, n. 1, p. 91-108, jan./jun. 1999.

ROUDINESCO, E.; PLON, M. Dicionário de psicanálise. Trad. Vera

Ribeiro e Lucy Magalhães. Rio de Janeiro: Jorge Zahar, 1998. 
Psicanálise aplicada ao estudo do cotidiano escolar

STAROBINSKI, J. Prefácio. In: JONES, E. Hamlet et Oedipe. Paris: Gallimard, 1980. p. I-XL.

Flávia Zanni Siqueira, mestranda em Educação na área de concentração Psicologia e Educação pela Universidade de São Paulo (USP), é coordenadora de projetos no Instituto Social para Motivar, Apoiar e Reconhecer Talentos (Ismart).

fzsiqueira@yahoo.com.br

Recebido em 12 de abril de 2010.

Aprovado em 16 de setembro de 2010. 